\title{
EZH2, Endothelin-1, and CD34 as Biomarkers of Aggressive Cervical Squamous Cell Carcinoma: An Immunohistochemical Study
}

\author{
Anan FATHY, Aziza E. ABDELRAHMAN iD \\ Department of Pathology, Zagazig University, Faculty of Medicine, ZAGAZIG, EGYPT
}

ABSTRACT

Objective: Cervical cancer has an increasing incidence in developing countries with a predominance of squamous cell carcinoma. In this work, we aimed to analyze the role of EZH2, Endothelin-1, and CD34 as indicators of the aggressiveness in cervical squamous cell carcinoma.

Material and Method: Immunohistochemical expression of EZH2, Endothelin-1, and CD34 was studied in 54 paraffin-embedded tissue specimens of cervical squamous cell carcinoma. Their correlation to the clinicopathologic features and the potential angiogenic role were analyzed.

Results: High EZH2 expression was noted in 78\% of cervical squamous cell carcinoma with a significant relation with tumor grade, FIGO stage and lymph node metastasis ( $\mathrm{p}=<0.001, \mathrm{p}=0.007, \mathrm{p}=0.03$ respectively). Endothelin- 1 overexpression was detected in $63 \%$ of the studied cases with a significant association with tumor size, FIGO stage and lymph node metastasis ( $\mathrm{p}=0.009, \mathrm{p}=0.002, \mathrm{p}=0.02$ respectively). High CD34 expression (MVD) was noted in $56 \%$ of the cases and associated with the tumor size, FIGO stage and lymph node metastasis $(\mathrm{p}<0.001, \mathrm{p}<0.001, \mathrm{p}=0.04$ respectively). The three markers were significantly associated $(\mathrm{p}<0.05)$.

Conclusion: EZH2, ET-1, and CD34 may act as biomarkers of aggressive cervical squamous cell carcinoma. They may contribute to the signaling pathway of angiogenesis. Therefore, they could potentially be used in targeted therapy.

Key Words: EZH2, Endothelin-1, CD34, Immunohistochemistry, Uterine cervical cancer

\section{INTRODUCTION}

Cervical cancer is one of the most frequent malignant tumors affecting women nowadays (1). Squamous cell carcinoma is regarded as the predominant subtype of cervical cancer (2). Despite the standardized treatment of cervical cancer; prediction of the patient's clinical outcome remains an actual issue. Therefore, indicators of disease aggressiveness are needed (1).

Enhancer of Zeste homolog 2 (EZH2) is a member of the polycomb group protein. Its oncogenic activity has been suggested to be through silencing tumor suppressor genes. Moreover, EZH2 could be implicated in tumor proliferation, metastasis, and angiogenesis (3).

Endothelin (ET) system is thought to have a role in cancer biology. It is formed by endothelial cells and consists of 21 amino acids, and 4 isomers ET-1, ET-2, ET-3, and ET-4. In addition to its vasoconstrictive effect, it plays a crucial role in promoting DNA synthesis, expression of proto-oncogene and cell proliferation owing to its growth factor-like effect (4). ET can play a crucial role in tumor

(Turk Patoloji Derg 2018, 34:150-157)

Received : 16.01.2018 Accepted : 04.03.2018 angiogenesis through binding to the surface receptors, endothelin receptor A (ETAR) and endothelin receptor B (ETBR), in a paracrine or autocrine manner (5)

Tumor angiogenesis and metastatic spread are two interconnected processes, which may contribute to cancer associated death. Thus, novel strategies to target both of them are needed (6). Neo-angiogenesis occurs through an interaction between pro- and anti-angiogenic signals induced by endothelial and stromal tumor cells (7).

CD34 is a sialomucin family related Ag which is expressed on hematopoietic stem cells, progenitor cells and endothelial cells of small vessels. Anti-CD34 antibody can be used as a marker for vascular endothelial cells that enables quantitative analysis of microvascular density (MVD) (8).

The current study aimed to investigate the immunohistochemical expression of EZH2, ET-1 and CD34 in cervical squamous cell carcinoma (CSCC). Furthermore, their angiogenic role and the correlation with the clinicopathologic features were investigated.

Correspondence: Aziza E. ABDELRAHMAN

Department of Pathology, Zagazig University, Faculty of Medicine ZAGAZIG 44519, EGYPT

E-mail: azaelsayed@gmail.com Phone: +00201068743218 


\section{MATERIALS and METHODS}

\section{Tissue Specimens}

A retrospective study was done in the Pathology department of Zagazig University, including 54 formalinfixed, paraffin-embedded tissue specimens of cervical squamous cell carcinoma that were received between April 2009 and December 2012. The patients' clinical data were retrieved from their medical records. No preoperative radiotherapy or chemotherapy was documented. In the current study, one section of each paraffin block was stained with hematoxylin and eosin (H\&E). The tumor grade was evaluated according to the World Health Organization (WHO) standards. The staging was done according to the 2009 International Federation of Gynecology and Obstetrics (FIGO) criteria (9). The study complied with the guidelines of the local ethics committee in our University.

\section{Immunohistochemistry}

Paraffin sections of 4 um were stained using the streptavidin-biotin-peroxidase technique. The tissue sections were deparaffinized in xylene and rehydrated through graded alcohol. Epitope retrieval by boiling in citrate buffer ( $\mathrm{pH} \mathrm{6.0)}$ ) for 20 min was done and then washed in phosphate buffer saline (PBS). Endogenous peroxidase activity was blocked by incubation of slides in $3 \%$ hydrogen peroxide for 20 minutes. After washing with PBS, blocking serum was applied for $10 \mathrm{~min}$. At room temperature, the tissue sections were incubated overnight with polyclonal anti-EZH2 antibody (1:100, GTX82503BD, Gene Tex); polyclonal anti-Endothelin-1 antibody (1:100, GTX116033, Gene Tex) and monoclonal anti-CD34 antibody (ready to use, clone QB End/10, Cat \#MS-363-R7, Thermo scientific). After rinsing in PBS, the tissues were incubated with a biotin-conjugated secondary antibody (Lab Vision Corporation, Fremont, USA) and then incubated using the streptavidin-biotin system for 1 hour at room temperature. The sections were incubated with diaminobenzidine (DAB) for 15 minutes then rinsed with distilled water. Finally, the slides were counterstained with Meyer's hematoxylin, dehydrated and mounted. Negative controls were made by a substitution of primary antibodies with a non-immune serum. Breast ductal carcinoma was used as positive control for both EZH2 and endothelin-1 and the tonsils for CD34.

\section{Analysis of EZH2 Immunostaining}

Brownish nuclear staining of tumor cells was evaluated as positive immunoreactivity. A final staining score (0-9) was obtained by multiplying both the staining intensity (0: negative; 1 : mild; 2 : moderate; 3 : strong) and the percentage of positive cells $(0-33 \%$, score $1 ; 34-66 \%$, score 2 and $>67 \%$, score 3 ). A final score of $\geq 4$ was considered as high immunoexpression (10).

\section{Analysis of Endothelin-1 Immunostaining}

Cytoplasmic brownish discoloration of tumor cells was considered as positive immunoexpression. An immunoreactivity score was calculated by multiplying both staining intensity (Score 0: negative, 1: week, 2: moderate, and 3: strong staining) and distribution of stained cells $(0:<10 \%$, 1: $10 \%-30 \%, 2: 30 \%-70 \%$, and $3:>70 \%$ of cells) (11). We considered final score values (2-4) as low ET-1expression and score values $(6,9)$ as high expression.

\section{Evaluation of MVD Stained by CD34}

We searched for areas of high vascularity (hot spots) within the tumor using low power, and then we used high power to count the number of micro vessels in 3 fields of this area. Then the highest value among the three fields was obtained for analysis. Any brown stained endothelial cell or clusters of endothelial cells with or without lumen was counted as single micro vessel (12). We calculated the median for 54 cases and used it as a cutoff point. Values more than this point were considered as high MVD and that below it was considered as low.

\section{Statistical Analysis}

The collected data were computerized and statistically analyzed using SPSS program (Statistical Package for Social Science) version 18.0. Qualitative data were represented as frequencies and relative percentages. Chisquare test and the fisher exact test were used to calculate the difference between qualitative variables. Quantitative data were expressed as mean \pm SD (standard deviation). The significance level of the mentioned statistical tests was done and the threshold of significance is fixed at 5\% level ( $\mathrm{p}$-value), where the $\mathrm{p}$ value of $>0.05$ indicates nonsignificant results, a $\mathrm{p}$ value of $<0.05$ indicates significant results and a $\mathrm{p}$ value of $<0.01$ indicates highly significant results.

\section{RESULTS}

\section{Clinicopathologic Features}

The mean age of cancer patients at the initial diagnosis was $51.22 \pm 13.55$. The majority of the primary tumors $(52 \%$, 28/54) were measured $\leq 4 \mathrm{~cm}$. According to WHO; $56 \%$ (30/54) of the tumors were GI\&II, while the remaining cases were GIII. Stage Ib1 was the predominant stage (57\%, 31/54) in the studied cases. Lymph node metastasis was detected in 35\% (19/54) of the cases (Table I). 
Table I: Clinicopathological features of 54 cases of cervical squamous cell carcinoma

\begin{tabular}{lll}
\hline Variables & No. & $\%$ \\
\hline Age & & \\
$\quad \leq 50$ & 31 & $57 \%$ \\
$>50$ & 23 & $43 \%$ \\
\hline Size & & \\
$\quad \leq 4 \mathrm{~cm}$ & 28 & $52 \%$ \\
$>4 \mathrm{~cm}$ & 26 & $48 \%$ \\
\hline Grade & & \\
$\quad$ GI\&II & 30 & $56 \%$ \\
$\quad$ GIII & 24 & $44 \%$ \\
\hline FIGO stage & & \\
Ib1 & 31 & $57 \%$ \\
Ib2-IIb & 23 & $43 \%$ \\
\hline LN metastasis & & \\
$\quad$ +ve & 19 & $35 \%$ \\
-ve & 35 & $65 \%$ \\
\hline EZH2 & & \\
Low & 12 & 22 \\
High & 42 & 78 \\
\hline ET-1 & & \\
Low & 20 & 37 \\
High & 34 & 63 \\
\hline CD34 & & 44 \\
Low & 24 & 56 \\
High & 30 & \\
\hline
\end{tabular}

LN: Lymph node

\section{EZH2 Expression}

EZH2 high expression was noted in 78\% (42/54) of CSCC, while low expression in the remaining cases (Figure 1A$C)$. High EZH2 expression exhibited a high significant association with the tumor grade $(p<0.001)$, FIGO stage $(p=0.007)$ and lymph node metastasis $(p=0.03)$. No significant association between high EZH2 expression and patient age or primary tumor size was detected $(\mathrm{p}=0.46$, $\mathrm{p}=0.07$ respectively) (Table II).

\section{Endothelin-1 Expression}

High ET-1 expression was noted in 63\% (34/54) of CSCC cases (Figure 2A,B). A significant association with the tumor size, FIGO stage and lymph node metastasis ( $p=0.009, p=0.002$, and $p=0.02$ respectively) was found. However, no significant association with the patient age or tumor grade was detected ( $p=0.16, p=0.10$ respectively) (Table III).
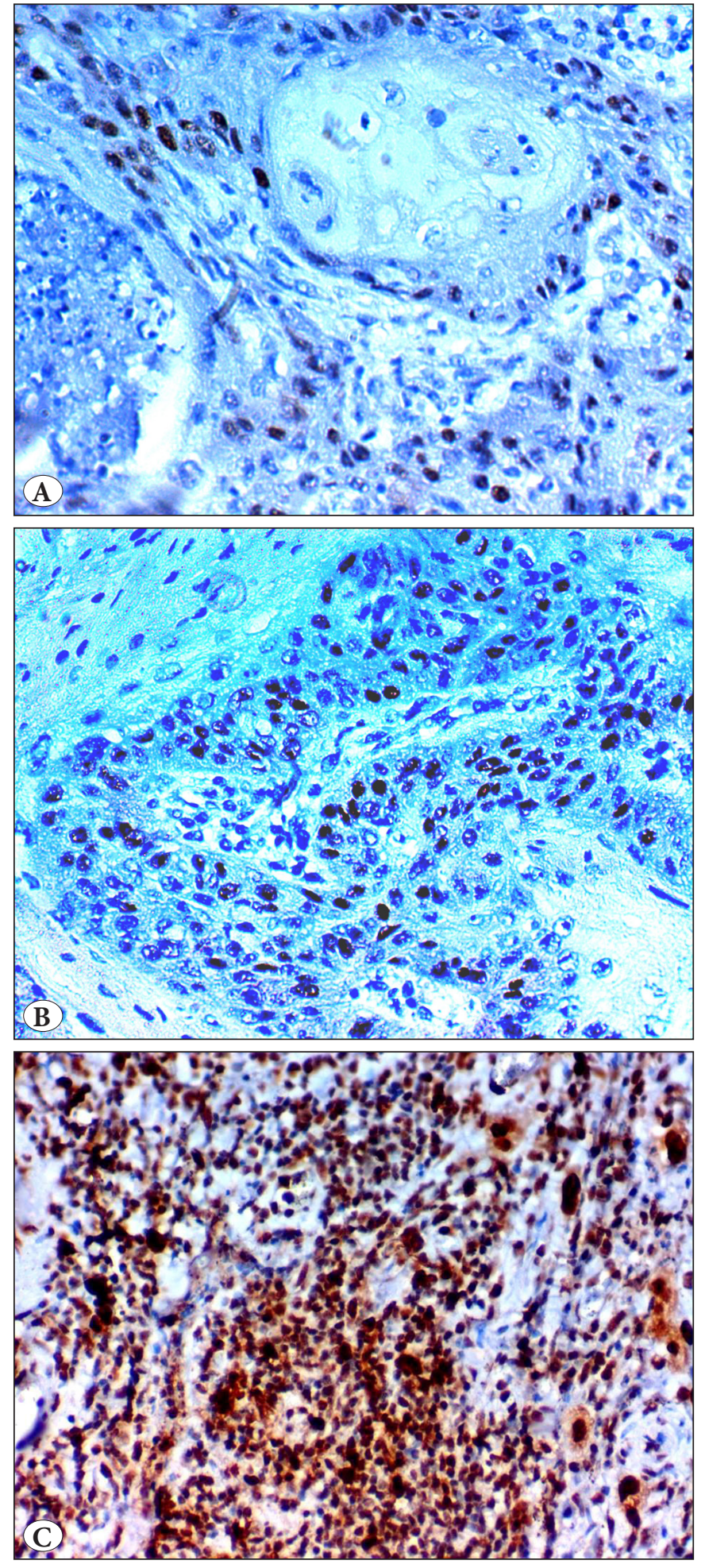

Figure 1: EZH2 nuclear expression in CSCC. A) Low nuclear EZH2 expression in a case of grade I CSCC (IHC; x400). B) Low nuclear EZH2 expression in a case of grade II CSCC (IHC; $\mathrm{x} 400$ ). C) High nuclear EZH2 expression in a case of grade III CSCC (IHC; x400). 
Table II: The association of EZH2 with the clinicopathologic features

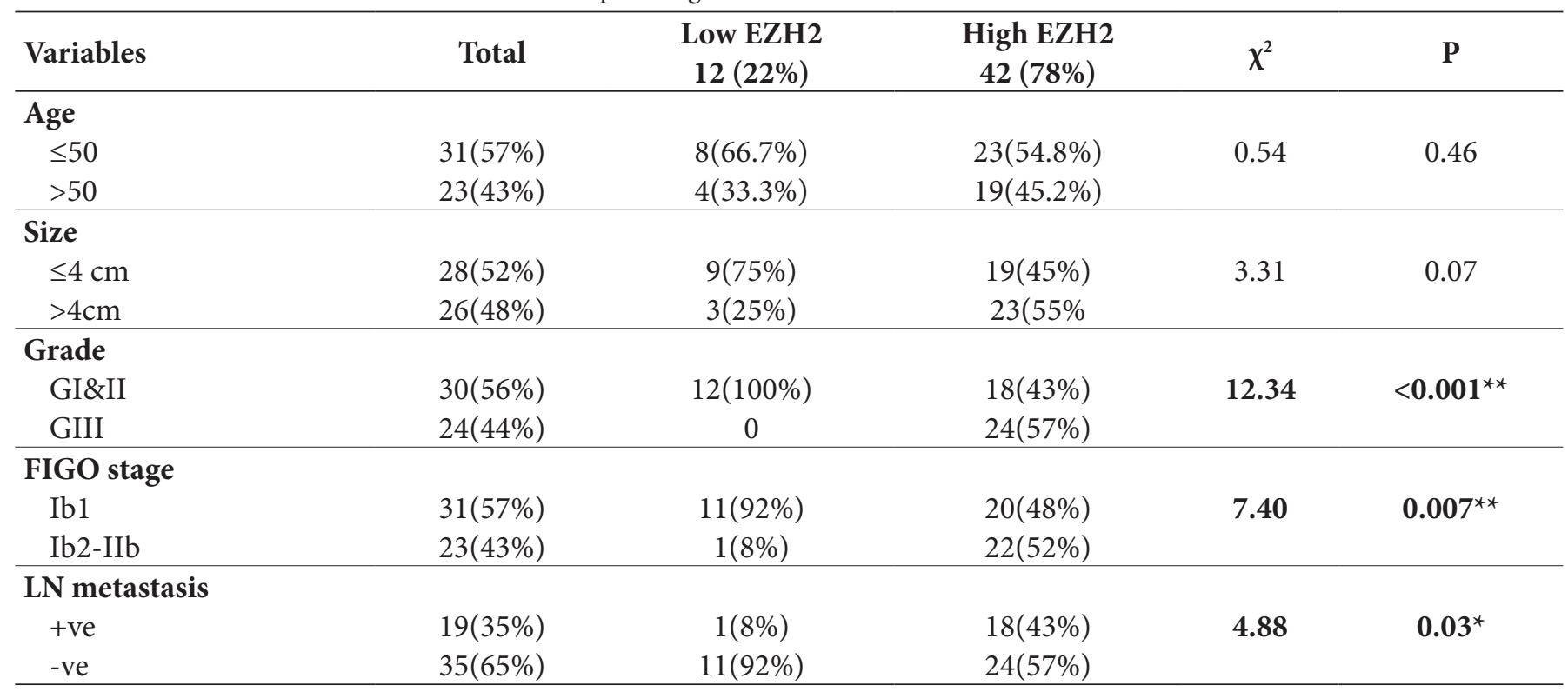

LN: Lymph node. ${ }^{\star}$ Significant value, ${ }^{* *}$ Highly significant value

Table III: The association of ET-1 with the clinicopathologic features

\begin{tabular}{|c|c|c|c|c|c|}
\hline Variables & Total & $\begin{array}{c}\text { Low ET-1 } \\
20(37 \%) \\
\end{array}$ & $\begin{array}{c}\text { High ET-1 } \\
34(63 \%)\end{array}$ & $\chi^{2}$ & $\mathbf{P}$ \\
\hline \multicolumn{6}{|l|}{ Age } \\
\hline$\leq 50$ & $31(57 \%)$ & $9(45 \%)$ & $22(64.7 \%)$ & 2 & 0.16 \\
\hline$>50$ & $23(43 \%)$ & $11(55 \%)$ & $12(35.3 \%)$ & & \\
\hline \multicolumn{6}{|l|}{ Size } \\
\hline$\leq 4 \mathrm{~cm}$ & $28(52 \%)$ & $15(80 \%)$ & $13(38.2 \%)$ & 6.82 & $0.009^{* *}$ \\
\hline$>4 \mathrm{~cm}$ & $26(48 \%)$ & $5(20 \%)$ & $21(61.8 \%)$ & & \\
\hline \multicolumn{6}{|l|}{ Grade } \\
\hline GI\&II & $30(56 \%)$ & $14(70 \%)$ & $16(47 \%)$ & 2.68 & 0.10 \\
\hline GIII & $24(44 \%)$ & $6(30 \%)$ & $18(53 \%)$ & & \\
\hline \multicolumn{6}{|c|}{ FIGO stage } \\
\hline Ib1 & $31(57 \%)$ & $17(85 \%)$ & $14(41 \%)$ & 9.89 & $0.002^{* *}$ \\
\hline Ib2-IIb & $23(43 \%)$ & $3(15 \%$ & $20(59 \%)$ & & \\
\hline \multicolumn{6}{|c|}{ LN metastasis } \\
\hline$+\mathrm{ve}$ & $19(35 \%)$ & $3(15 \%)$ & $16(47.1 \%)$ & 5.68 & $0.02^{\star}$ \\
\hline -ve & $35(65 \%)$ & $17(85 \%)$ & $18(52.9 \%)$ & & \\
\hline
\end{tabular}

LN: Lymph node. ${ }^{\star}$ Significant value, ${ }^{\star *}$ Highly significant value

\section{CD34 Expression and the Evaluation of MVD}

The MVD of our 54 CSCC patients ranged from 12 to 41 with median: 24.5. High MVD ( $\geq 25)$ was found in $56 \%(30 / 54)$ of cases and low MVD $(<25)$ in the remaining specimens (Figure 3A-C). A statistically significant association of larger primary tumor size, higher FIGO stage and positive lymph node metastasis with the high MVD was detected $(p<0.001, p<0.001$, and $p=0.04$ respectively). Neither the patient age nor the degree of tumor differentiation showed a significant association with the MVD ( $p=0.33, p=0.14$ respectively) (Table IV).

\section{Association of EZH2, ET-1 and CD34 (MVD) Expression}

Tumors with increased MVD showed a high EZH2 expression and high ET-1 expression with a significant difference ( $p=0.02, p<0.001$ respectively). A significant positive association between high EZH2 and high ET-1 was detected $(p<0.001)$ (Table V). 

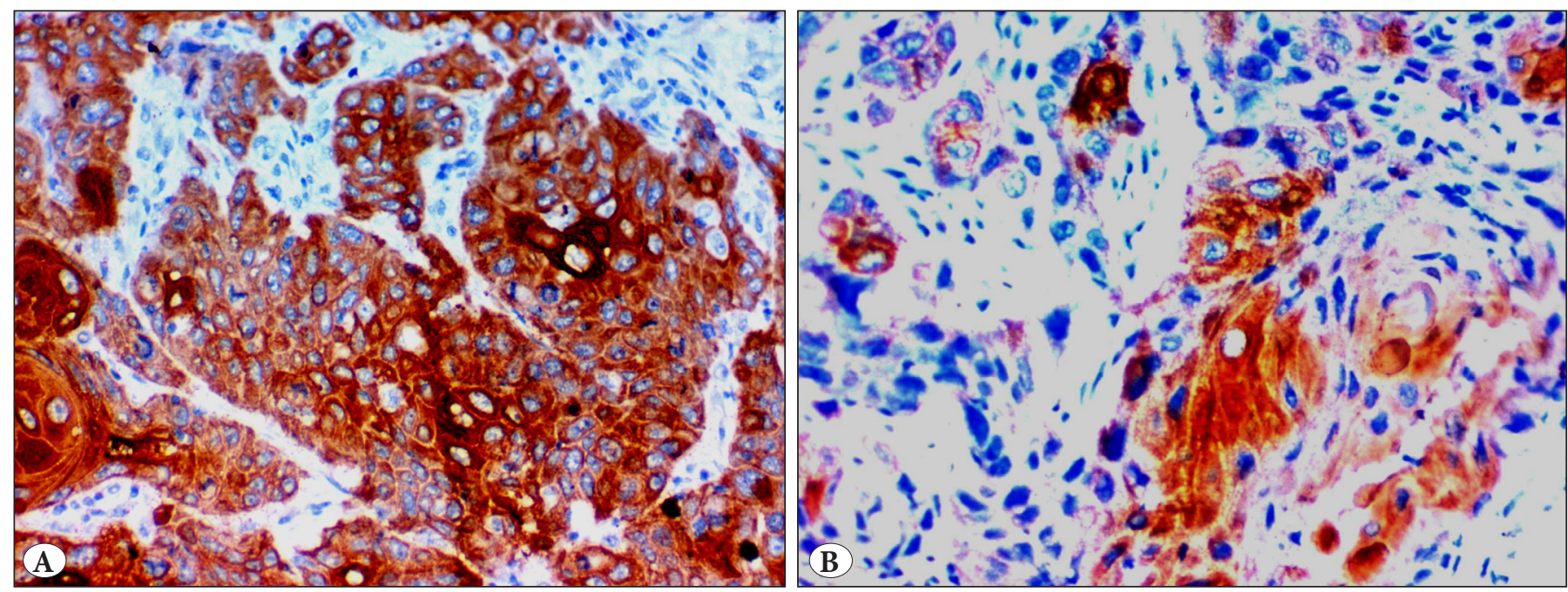

Figure 2: ET-1 cytoplasmic expression in CSCC. A) High ET-1 expression in a case of grade I CSCC (IHC; x400). B) Low ET-1 expression in a case of grade III CSCC (IHC; $x 400)$.
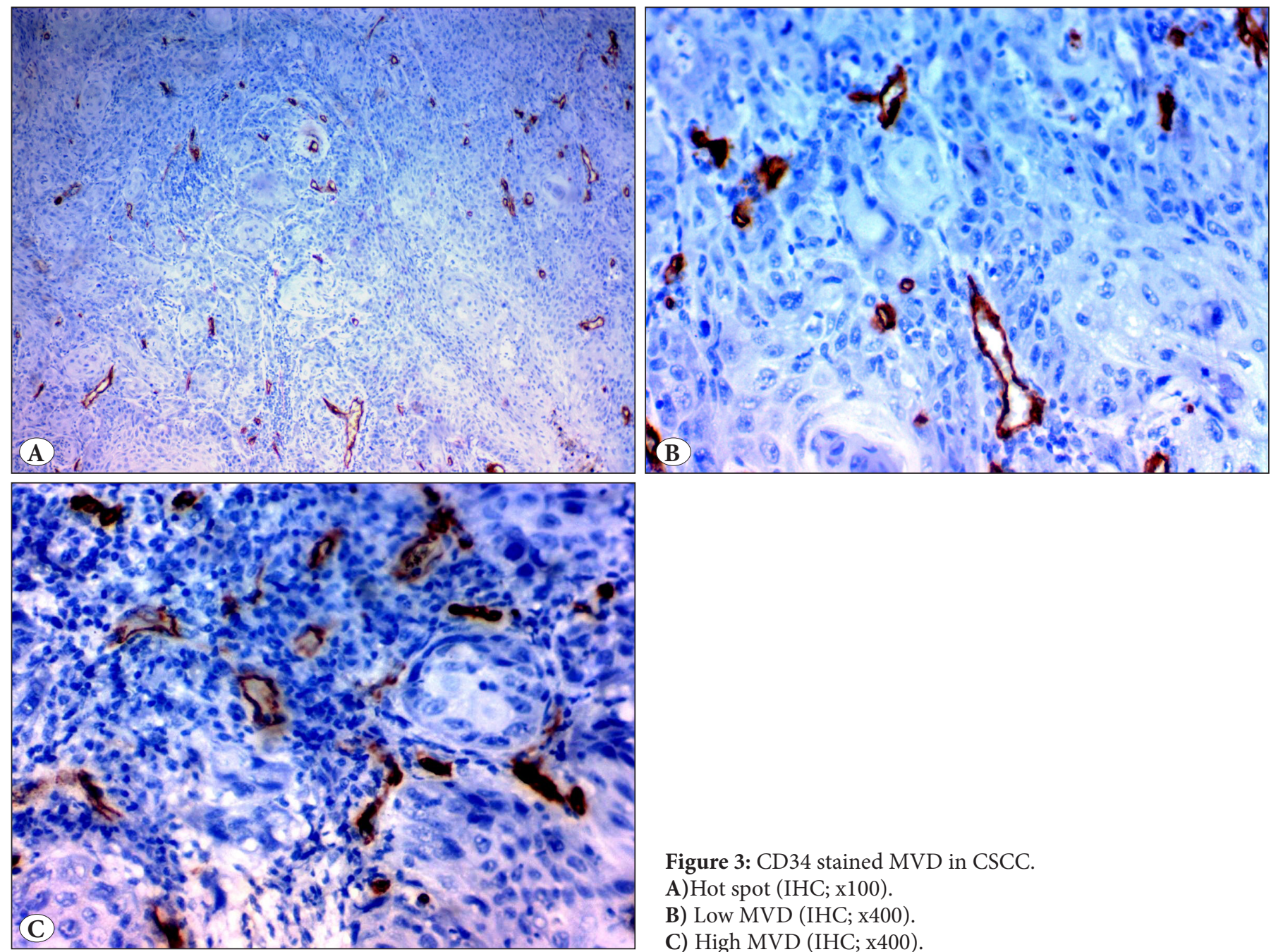

Figure 3: CD34 stained MVD in CSCC.

A)Hot spot (IHC; x100).

B) Low MVD (IHC; x400).

C) High MVD (IHC; x400). 
Table IV: The association of MVD with the clinicopathologic features

\begin{tabular}{|c|c|c|c|c|c|}
\hline Variables & NO. & $\begin{array}{c}\text { Low MVD } \\
24(44 \%)\end{array}$ & $\begin{array}{c}\text { High MVD } \\
30(56 \%)\end{array}$ & $\chi^{2}$ & $\mathbf{P}$ \\
\hline \multicolumn{6}{|l|}{ Age } \\
\hline$<50$ & $31(57 \%)$ & $12(50 \%)$ & $19(63.3 \%)$ & 0.97 & 0.33 \\
\hline$\geq 50$ & $23(43 \%)$ & $12(50 \%)$ & $11(36.7 \%)$ & & \\
\hline \multicolumn{6}{|l|}{ Size } \\
\hline$\leq 4 \mathrm{~cm}$ & $28(52 \%)$ & $22(92 \%)$ & $6(20 \%)$ & 27.34 & $<0.001^{\star *}$ \\
\hline$>4 \mathrm{~cm}$ & $26(48 \%)$ & $2(8 \%)$ & $24(80 \%)$ & & \\
\hline \multicolumn{6}{|l|}{ Grade } \\
\hline GI\&II & $30(56 \%)$ & $16(67 \%)$ & $14(47 \%)$ & 2.16 & 0.14 \\
\hline GIII & $24(44 \%)$ & $8(33 \%)$ & $16(53 \%)$ & & \\
\hline \multicolumn{6}{|c|}{ FIGO stage } \\
\hline Ib1 & $31(57 \%)$ & $22(83 \%)$ & $9(3 \%)$ & 20.74 & $<0.001^{\star *}$ \\
\hline Ib1-IIb & $23(43 \%)$ & $2(17 \%)$ & $21(70 \%)$ & & \\
\hline \multicolumn{6}{|c|}{ LN metastasis } \\
\hline$+\mathrm{ve}$ & $19(35 \%)$ & $5(20 / 8 \%)$ & $14(46.7 \%)$ & 3.90 & $0.04^{\star}$ \\
\hline -ve & $35(65 \%)$ & $19(79.8 \%)$ & $16(53.3 \%)$ & & \\
\hline
\end{tabular}

LN: Lymph node. ${ }^{\star}$ Significant value, ${ }^{\star *}$ Highly significant value

Table V: Relation between EZH2, ET-1 and CD34 (MVD) expression in 54 cases of cervical squamous cell carcinoma

\begin{tabular}{|c|c|c|c|c|c|c|c|c|c|c|c|}
\hline \multirow[b]{2}{*}{ Variable } & & & \multicolumn{3}{|c|}{ EZH2 } & \multicolumn{3}{|c|}{ ET-1 } & \multicolumn{3}{|c|}{ CD34(MVD) } \\
\hline & & & Low & High & $\mathbf{n}$ & Low & High & $\mathbf{n}$ & $<$ (low) & $>$ (high) & \\
\hline \multirow{3}{*}{ EZH2 } & & & \multirow{3}{*}{\multicolumn{2}{|c|}{ - }} & & 4 & 4 & \multirow{3}{*}{$<0.001^{\star *}$} & & & \multirow{3}{*}{$0.02^{*}$} \\
\hline & Low & 12 & & & & 11 & 1 & & 9 & 3 & \\
\hline & High & 42 & & & & 9 & 33 & & 15 & 27 & \\
\hline \multirow{2}{*}{ ET-1 } & Low & 20 & 11 & 9 & \multirow{2}{*}{$<0.001^{\star *}$} & & \multirow{2}{*}{------- } & & 18 & 2 & \multirow{2}{*}{$<0.001^{* *}$} \\
\hline & High & 34 & 1 & 33 & & & & & 6 & 28 & \\
\hline CD34 & Low & 24 & 9 & 15 & \multirow{2}{*}{$0.02^{\star}$} & 18 & 6 & \multirow{2}{*}{$<0.001^{\star \star}$} & \multirow{2}{*}{\multicolumn{2}{|c|}{------ }} & \\
\hline (MVD) & High & 30 & 3 & 27 & & 2 & 28 & & & & \\
\hline
\end{tabular}

${ }^{\star}$ Significant value, ${ }^{\star *}$ Highly significant value

\section{DISCUSSION}

Cervical cancer is associated with a high rate of female mortality, especially in developing countries. High recurrence rate, chemotherapeutic resistance with reduced survival is more common with advanced cervical cancer. Early diagnosis, targeted therapy, and prediction of prognosis are of great clinical significance (13). Therefore, the use of biomarkers that can predict the progression of tumor and evaluate the therapeutic strategies is mandatory (14).

EZH2 is the catalytic core subunit of polycomb repressive complex 2 (PRC2). PRC2 methylated lysine 27 of histone $\mathrm{H} 3$ (H3K27) and lysine 9 of histone H3 (H3K9) to induce transcriptional silencing. EZH2 can induce epithelialmesenchymal transition (EMT) directly by repressing the expression of E-cadherin through histone H3K27 trimethylation, or indirectly by inhibiting miR-361 which is a Twist suppressor (15). This could explain our findings as regards the presence of significant relation between high EZH2 expression and advanced FIGO stage and the presence of lymph node metastasis in CSCC cases.

Regarding the tumor grade, a significant association of high EZH2 expression with high-grade tumors was detected. Other studies agreed with our results and reported that EZH2 expression has been linked to tumor aggressiveness and invasion. Thus, it could predict the risk of tumor progression $(3,16,17)$.

ET- 1 can act as a tumorigenic and angiogenic factor. Altered expression of ET-1 or its receptors has been detected in many tumors. (18). The present study showed a significant association of ET-1 expression with the advanced stage of CSCC cases and positive lymph node metastasis. 
Similarly, high ET-1 expression and higher stages of laryngeal carcinoma were found to be associated in other studies $(7,19)$. This could be explained by the fact that the ET-1/ETAR axis can promote EMT, thus enhancing invasion and metastasis. In addition, it can promote proliferation and evasion of apoptosis (5). This may explain the significant association of high ET-1 expression with larger primary tumor size in our study. Wülfing et al showed that high ET-1 expression was associated with a larger size of primary breast tumor (20). On the other hand, Huang et al noted that high Endothelin-1 expression was associated with early tumor stage and absence of lymph node involvement in the upper urinary tract study. They reported that ETBR dominant tumors have a better prognosis (21).

Tumor angiogenesis is essential for the growth and metastatic spread of neoplasms. The angiogenic degree of tumor is strongly associated with its aggressiveness and can determine its clinical outcome (22). It was suggested that most tumors microvascular networks have significant abnormalities in morphology and architecture. These can resist blood flow, increase the transvascular fluid flow, decrease perfusion with inadequate oxygen and nutrient supply (23). Therefore, nutrient deficiency, increased pressure of interstitial fluid and hypoxia characterize the microenvironment of many tumors. These features may favor metastasis and tumor proliferation (24). Measurement of MVD by immunostaining of endothelial marker as CD34 is used for angiogenesis evaluation. A significant association between intra-tumoral MVD and the prognosis of many tumors was published (25).

In this study, the analysis of the MVD relation with clinicopathologic features of CSCC cases revealed a significant association with the primary tumor size. This observation was similar to the previous studies $(12,25,26)$ that were done on colorectal carcinoma, breast cancer and oral squamous cell carcinoma respectively.

Looking for tumor stage, high MVD was significantly associated with the advanced tumor stage. This matches the results of other studies $(8,12,27)$ on cervical and colonic carcinomas. As regards lymph node metastasis, a significant relationship with the high MVD was found. The same result was obtained by Rofstad et al who reported that increased neo-angiogenesis in tumor tissues illustrated the direct spread to lymph nodes in cervical cancer (24). Such a correlation was reported by another study on breast cancer (25). By contrast, another study found no correlation between MVD and clinicopathologic variables (28). Tumor heterogeneity, the type of the endothelial marker used, hot spot selection and counting, angiogenesis heterogeneity, methods of detection and observer variability could explain these discrepancies (25).

On studying the potential involvement of EZH2 in angiogenesis of squamous cell carcinoma of the cervix; we noted that tumors with high EZH2 expression showed high MVD with statistical significance. It was suggested that EZH2 could affect cancer angiogenesis as it has genes repressor role (7). It helps cancer stem cell self-renewal; cancer stem cells are the seeds of metastatic spread and can differentiate into tumor-associated endothelial cells (17).

On evaluating the role of ET- 1 in angiogenesis of CSCC, a significant positive relation between high ET-1 expression and high MVD was detected. Endothelin-1 can regulate neo-vascularization by controlling migration, proliferation, and tubule formation of endothelial cells. It can also induce MVD and vascular endothelial growth factor in neoplastic cells, promoting angiogenesis of tumors (29).

The presence of a positive significant association between EZH2, ET-1 and CD34 in CSCC tissues indicated their contribution in the signaling pathway for angiogenesis. Such a correlation was detected in a study on nasopharyngeal carcinoma. They proved that EZH2 can promote angiogenesis through inhibition of mir-1/ET-1 axis. Mechanistic work of that study revealed that EZH2 inhibits miR-1 transcription through promoter binding activity, with the result of increased ET-1 expression which is suppressed by miR-1. Furthermore, EZH2 knockdown or miR-1 overexpression induces anti-angiogenic effect on nasopharyngeal carcinoma cells (7). Further experimental and mechanistic study is needed to prove the angiogenic pathway in CSCC.

In conclusion, EZH2, ET-1, and CD34 may act as biomarkers of aggressive cervical squamous cell carcinoma. They may contribute in the signaling pathway of angiogenesis. Therefore, they could be used as a potential targeted therapy.

\section{CONFLICT OF INTEREST}

The authors declare that they have no conflict of interest

\section{FUNDING}

This research received no specific grant from any funding agency in the public, commercial, or not-for-profit sectors.

\section{REFERENCES}

1. Chen S, Zhang H, Li J, Jiang H, Fan L, Kong L, Yao S. Analyzing simultaneous positive expression of EZH2 and P53 protein to improve predictive value in cervical squamous cell carcinoma. Int J Gynecol Cancer. 2014; 24:1653-8. 
2. Miller R, Waters L, Mody D, Tams K. Squamous cell carcinoma of the cervix. A cytology-histology-human papilloma virus correlation in clinical practice.Arch Pathol Lab Med. 2015;139:776-81.

3. Azizmohammadi S, Azizmohammadi S, Safari A, Kaghazian M Sadrkhanlo M, Behnod V, Seifoleslami M. High-level expression of RIPK4 and EZH2 contributes to lymph node metastasis and predicts favorable prognosis in patients with cervical cancer. Oncol Res. 2017;25:495-501.

4. Zhang Z, Chen L, Xu W, Sigdel K, Jiang X. Effects of silencing endothelin-1 on invasion and vascular formation in lung cancer. Oncol LET. 2017;13:4390-6.

5. Irani S, Salajegheh A, Smith R, Lam A. A review of the profile of endothelin axis in cancer and its management. Crit Rev Oncol Hematol. 2014;89:314-21.

6. Crea F, Fornaro L, Bocci G, Sun L, Farrar W, Falcone A, Danesi R. EZH2 inhibition: Targeting the crossroad of tumor invasion and angiogenesis. Cancer Metastasis Rev. 2012;31:753-61.

7. Lu J, Zhao F, Peng Z, Zhang M, Lin S, Liang B, Zhang B, Liu X, Wang L, Li G, Tian W, Peng Y, He M, Li X. EZH2 promotes angiogenesis through inhibition of miR-1/ Endothelin-1 axis in nasopharyngeal carcinoma. Oncotarget. 2014;5:11319-32.

8. Ancuța C, Ancuța E, Zugun-Eloae F, Carasevici E. Neoangiogenesis in cervical cancer: Focus on CD34 assessment. Rom J Morphol Embryol. 2010;51:289-94.

9. Pecorelli S, Zigliani L, Odicino F. Revised FIGO staging for carcinoma of the cervix. Int J Gynaecol Obstet. 2009;105:107-8.

10. Matsika A, Srinivasan B, Day C, Mader SA, Kiernan DM, Broomfield A, Fu J, Hooper JD, Kench JG, Samaratunga H. Cancer stem cell markers in prostate cancer: An immunohistochemical study of ALDH1, SOX2 and EZH2. Pathology. 2015;47:622-8.

11. Papanikolaou S, Bravou V, Papadaki H, Gyftopoulos K. The role of the endothelin axis in promoting epithelial to mesenchymal transition and lymph node metastasis in prostate adenocarcinoma. Urol Ann. 2017;9:372-9.

12. Mohamed H, Abd El All H, Kamel A, Yossef W, Hammam M. Correlation of vascular endothelial growth factor expression and neovascularization with colorectal carcinoma: A pilot study. J. Adenocarcinoma. 2016;1:1.

13. Cao X, Lu H, Zhang L, Chen L, Gan M. MEKK3 and Survivin expression in cervical cancer: Association with clinicopathological factors and prognosis. Asian Pac J Cancer Prev. 2014;15:5271-6.

14. Sun B, Ye X, Li Y, Zhang W. Lgr5 is a potential prognostic marker in patients with cervical carcinoma. Int J Clin Exp Pathol. 2015;8:1783-9.

15. Zhang Q, Dong P, Liu X, Sakuragi N, Guo S. Enhancer of Zeste homolog 2 (EZH2) induces epithelial-mesenchymal transition in endometriosis. Sci Rep. 2017;7:6804.
16. Jin M, Yang Z, YeW, Yu X, Hua X. Prognostic significance of histone methyltransferase enhancer of zeste homolog 2 in patients with cervical squamous cell carcinoma. Oncol Lett. 2015; 10:857-62.

17. Liu Y, Liu T, Bao X, He M, Li L, Yang X. Increased EZH2expression is associated with proliferation and progression of cervical cancer and indicates a poor prognosis. Int J Gynecol Pathol. 2014; 33:218-24.

18. Rosano L, Spinella F, Bagnato A. Endothelin -1 in cancer: Biological implications and therapeutic opportunities. Nat Rev Cancer. 2013;13:637-51.

19. Wang S, Wu J, Song Y, ZHON H. Expression of endothelin-1 in laryngocarcinoma tissues and its clinical significance. Oncol Lett. 2016;11:3366-8.

20. Wülfing P, Diallo R, Kersting C, Wülfing C, Poremba C, Rody A, Greb R, Böcker W, Kiesel L. Expression of endothelin-1, endothelin-A, and endothelin-B receptor in human breast cancer and correlation with long-term follow-up. Clin Cancer Res. 2003;9:4125-31.

21. Huang C, Chien T, Yang S,Li C, Li W, Lin H, Ke H, Wei Y, Yeh $\mathrm{B}$, Yeh $\mathrm{H}, \mathrm{Wu} \mathrm{W}$. High endothelin-1 expression predicts good prognosis in upper tract urothelial carcinoma. Int J Clin Exp Pathol. 2016;9:11697-707.

22. Benazzi C, Al-Dissi A, Chau C, Figg W, Sarli G, De Oliveira J, Gärtner F. Angiogenesis in spontaneous tumors and implications for comparative tumor biology. Scientific World Journal. 2014;2014:919570.

23. Cairns R, Papandreou I, Denko N. Overcoming physiologic barriers to cancer treatment by molecularly targeting the tumor microenvironment. Mol Cancer Res. 2006;4:61-70.

24. Rofstad E, Galappathi K, Mathiesen B. Tumor interstitial fluid pressure- A link between tumor hypoxia, microvascular density, and lymph node metastasis. Neoplasia. 2014;16:586-94.

25. Pyakurel D, Karki S, Agrawal C.A study on microvascular density in breast carcinoma. Journal of Pathology of Nepal. 2014;4:570-5.

26. Shahsavari F, Farhadi S, Sadri D, Sedehi M. Evaluation of microvascularity by CD34 expression in esophagus and oral squamous cell carcinoma. J Contemp Dent Pract. 2015;16:45862.

27. Vieira C, Silva B, Pinto A, Vassallo J, Moraes G, Santana O, Santos G, Carvasan A, Zeferino C. CD34 as a marker for evaluating angiogenesis in cervical cancer. Pathol Res Pract. 2005;201:313-8.

28. Chen Z, Xu S, Xu W, Huang J, Zhang G, Lei L, Shao X, Wang $\mathrm{X}$. Expression of cluster of differentiation 34 and vascular endothelial growth factor in breast cancer, and their prognostic significance. Oncol Lett. 2015;10:723-9.

29. Asgari M, Eftekhar E, Abolhasani M, Shahrokh H. Endothelin-1 expression in prostate needle biopsy specimens correlated with aggressiveness of prostatic cancer. Iran J Pathol. 2017;12:171-6. 